\title{
La reciente humanización del Derecho Civil español: necesidades $y$ retos en materia de discapacidad
}

\author{
Inmaculada Vivas Tesón ${ }^{1}$ \\ Universidad de Sevilla, España \\ ivivas@us.es
}

Hace más de veinte años -prefiero no decir exactamente cuántos- estudié mi carrera universitaria, en la cinco veces centenaria Facultad de Derecho de la Universidad de Sevilla, con un código civil hecho por y para hombres, adultos, propietarios, heterosexuales y sanos o normales -inaceptables términos con los que con más frecuencia de la debida se alude a las personas con discapacidad-. Creo que ello podría predicarse de todas las codificaciones civiles (europeas y latinoamericanas) pertenecientes a la familia del civil law que, herederos del derecho romano, siguieron la estela del code napoleónico.

Sin embargo, tengo ahora la gran suerte de vivir lo que llamo la "humanización del legislador civil". La situación de la mujer en el derecho civil español ha cambiado considerablemente. ${ }^{2}$ Los niños, niñas y adolescentes ya no son objetos de derecho, sino sujetos -si bien las normas

\footnotetext{
${ }^{1}$ Este trabajo se incluye entre los resultados del proyecto de investigación "Discapacidad, Enfermedad Crónica y Accesibilidad a los Derechos" (DER2016-80138-R) del Ministerio de Economía y Competitividad, así como del Grupo de Investigación SEJ617 "Nuevas dinámicas del Derecho privado Español y Comparado" del que soy responsable, del Grupo de investigación "Direito constitucional nas relaçôes privadas" coordinado por las profesoras Joyceane BEZERRA DE MENEZES e Uinie CAMINHA de la Universidad de Fortaleza (Brasil) y del Grupo de investigación "Autonomia, paternalismo jurídico e vulnerabilidades" coordinado por la profesora Thamis Ávila DALSENTER VIVEIROS DE CASTRO de la Pontifica Universidad Católica de Río de Janeiro (Brasil).

2 VIVAS TESÓN, I.: "La situación de la mujer en el Derecho Civil en Igualdad y mujer: las normas y su aplicación (1988-1998)", en Mujer e igualdad: la norma y su aplicación: aspectos constitucionales, penales y civiles, Instituto Andaluz de la Mujer, Sevilla, 1999, pp. 299-398.
} 
y la interpretación de las mismas siguen aún siendo adultocéntricas-. En nuestro ordenamiento, hoy tienen cabida las uniones estables y los matrimonios entre personas del mismo sexo, y desde hace unos años se han vuelto visibles las personas con discapacidad: ciudadanos plenos como todos los demás.

En la Antigüedad, se afirmaba que el pensamiento residía en el corazón. Aun hoy aprender de memoria se dice en francés apprendre par cour: aprender con el corazón. Actualmente, la relación mente-corazón está alcanzando mayor importancia para los operadores jurídicos (legisladores, jueces, abogados, fiscales, notarios, académicos...), aunque, en ocasiones sin faltar razón, parezcan carecer del segundo. Ello claramente se ve al abordarse jurídicamente la discapacidad, la cual es imposible afrontar con una mente que adolezca de analfabetismo emocional. Los impulsos normativos, los pronunciamientos judiciales, las aportaciones científicas, etc., solo pueden provenir de un profundo conocimiento de la realidad cotidiana y del corazón, de la empatía, de la sensibilidad hacia la diversidad y, sobre todo, del máximo respeto a la persona y a los derechos humanos.

Ello, por fortuna, está calando poco a poco no solo en España, sino en otros muchos países (Francia, Italia, Alemania, Austria, Portugal, Brasil, Perú...), a partir de la entrada en vigor de la Convención internacional de Naciones Unidas de los derechos de las personas con discapacidad (Nueva York, 2006), que está extendiéndose por todo el mundo como una-bendita- mancha de aceite. Es en el ámbito de la discapacidad donde se percibe la reciente "humanización" que están experimentando los legisladores nacionales e internacionales.

En 2008, año en que entró en vigor en el ordenamiento jurídico la Convención, dicho instrumento internacional nos colocaba ante una realidad existente pero, hasta entonces, invisible, pues las personas con discapacidad estaban encerradas en casas, manicomios o cárceles -en las que aún permanecen, indebidamente, muchas de ellas--. Gracias a este Tratado, ahora son visibles. Pero, por desgracia, ello va de la mano de un aumento de los delitos de odio por discapacidad, la disfobia, sobre la cual debemos poner nuestro empeño para erradicarla mediante una sola herramienta: la educación en igualdad y respeto. 
Puede afirmarse, sin temor a errar, que dicho Tratado internacional ha sido crucial en materia de derechos humanos por su impacto enorme; ha marcado un antes y un después en la evolución de los derechos de las personas diversamente capaces. Su aplicación ha supuesto, sin duda, avances importantísimos: en especial, la visibilización de las personas con discapacidad, poniendo el acento en la persona, y no en su deficiencia (con independencia del tipo, de la edad, del género y de que tenga o no la capacidad modificada judicialmente). Pero también es cierto que aún faltan muchos retos por alcanzar en su interpretación, grado de cumplimiento y desarrollo normativo. Lamentablemente, persisten numerosos escollos, tanto de hecho como jurídicos. Sigue habiendo sistemáticas vulneraciones de derechos.

La Convención onU ha conllevado, desde luego, un cambio paradigmático de actitud y enfoque respecto de la discapacidad a nivel mundial. Se mira con otros ojos, en clave de derechos humanos. Se advierte a España y a los restantes Estados, así como a las Organizaciones supranacionales (como la Unión Europea, que la ratificó en 2011) firmantes que el único abordaje que puede hacerse de la discapacidad es desde los derechos humanos y libertades fundamentales de la persona.

Para el Tratado de Nueva York hay que poner todos los medios al alcance para conocer la voluntad, deseos y preferencias de la persona con discapacidad. En este sentido, la Sentencia del Tribunal Supremo (Sala de lo civil, Sección $1^{\text {a }}$ ) del 30 de septiembre de 2014, señala: "a tenor de lo establecido en la Convención sobre los Derechos de las Personas con Discapacidad, la voluntad de la persona discapacitada (en el caso, incapacitada por decisión judicial) debe ser respetada salvo que razones objetivas permitan concluir que ello la perjudicaría".

Las diversas lecturas que del texto internacional he hecho a lo largo de esta década me han llevado siempre a la conclusión -que, incluso, he tenido ocasión de dejar escrita- de que la Convención de Nueva York no reconocía ningún derecho nuevo que no estuviera ya contenido en anteriores tratados internacionales. Sin embargo, hoy confieso discrepar conmigo misma. Estoy plenamente convencida de que, en efecto, reconoce con contundencia un nuevo derecho: el derecho a la accesibilidad universal (no solo arquitectónica, en la cual pensar por lo general); esto es, al ejercicio accesible y efectivo de todos los derechos para poder vivir 
una vida plena e independiente, incluido el derecho a elegir y a equivocarse en su recorrido vital. Solo así se cumple no solo lo dispuesto a la célebre "estrella polar" de la Convención, su art. 12, sino otro precepto que, a mi juicio, es igualmente crucial y, por ello, no tiene sentido uno sin el otro: el 19 y su reconocimiento al derecho a una vida independiente e inclusiva en la comunidad. Se trata de una disposición normativa transversal y, por lo tanto, interrelacionada con las restantes contenidas en el Tratado de Nueva York, pese a lo cual no suele prestársele tanta atención como al art. 12 .

En mi opinión, la accesibilidad se erige como un nuevo derecho de la personalidad. La no accesibilidad a los derechos es una flagrante violación de la dignidad humana: si los derechos reconocidos a todas las personas sin excepción no pueden disfrutarse plena $\mathrm{y}$, efectivamente, resulta imposible vivir una vida digna. Al respecto, conviene precisar que el respeto de los derechos humanos de las personas con capacidades diferentes no presenta solo un aspecto negativo o de abstención, sino también positivo o de acción, debiéndose, pues, adoptar todas las medidas necesarias para garantizar el ejercicio efectivo de aquéllos.

Según los principios, valores y mandatos contenidos en dicho Tratado internacional, se han producido significativos avances y conquistas en la inclusión y plena ciudadanía de las personas con diversidad funcional -cuatro millones de la población española, ${ }^{3}$ si bien debemos destacar que las estadísticas en materia de discapacidad son aún una asignatura pendiente-. Y siguen suscitándose importantes cambios jurídicos y de políticas públicas no solo en nuestro país, sino también en todos los Estados y organizaciones signatarios de este primer gran Tratado del sistema universal de derechos humanos del siglo XXI.

Entre los avances y logros alcanzados, cabe señalar que el ordenamiento jurídico español ha experimentado una profunda renovación terminológica. Las palabras demuestran cultura, el grado de civilización, el modo de pensar, respeto; no se trata de un mero lenguaje políticamente correcto; no es algo

\footnotetext{
${ }^{3}$ Los únicos datos estadísticos oficiales de los cuales disponemos en España son los de la Encuesta de Discapacidad, Autonomía personal y situaciones de Dependencia (conocida como EDAD) del Instituto Nacional de Estadística, publicada en noviembre de 2008 (si reparamos en la fecha, es más que probable que las cifras se hayan incrementado en estos años), conforme a la cual en nuestro país, alrededor de un $8,5 \%$ de la población, esto es, más de 3,8 millones de personas residentes en hogares españoles, por sexo, más de 2,30 millones de mujeres frente a 1,55 de hombres (puede consultarse en www.ine.es/prensa/np524.pdf).
} 
banal: cambiemos el lenguaje y cambiaremos el mundo. Por ello, hoy se habla de "personas con discapacidad" (no con "minusvalía") y del "procedimiento de modificación de la capacidad o de provisión de apoyos" (no de "incapacitación judicial"). No obstante, el art. 49 de la Constitución española de 1978 conserva todavía el término "disminuidos": "los poderes públicos realizarán una política de previsión, tratamiento, rehabilitación e integración de los disminuidos físicos, sensoriales y psíquicos, a los que prestarán la atención especializada que requieran y los ampararán especialmente para el disfrute de los derechos que este Título otorga a todos los ciudadanos". Con todo, el Consejo de Ministros aprobó en diciembre de 2018 un anteproyecto de reforma constitucional para eliminar esta palabra.

Por otra parte, ante la pasividad legislativa para enmendar las injustas cortapisas a los derechos de las personas con discapacidad, han sido los jueces y tribunales -a los que han de sumarse, por supuesto, otros operadores jurídicos- quienes, con cierta sensibilidad hacia los derechos de las personas con discapacidad, han cambiado, a golpe de sentencia, la visión de las cosas en este ámbito. Y si bien debemos felicitarnos por ello, tampoco se nos oculta que el respeto de los derechos y la dignidad de la persona diversamente capaz se ha convertido en una auténtica "lotería judicial", al depender de que toque un juzgador que conozca -e interprete adecuadamente, lo que no siempre ocurre- o no una norma de tan profundo calado. La existencia de la persona con diversidad funcional y el respeto de sus derechos y libertades no puede quedar al albur de sensibilidades y buenas voluntades, sino del estricto cumplimiento de un mandato normativo, y la Convención es una norma preceptiva y directamente vinculante. Ello no solo provoca una enorme inseguridad jurídica; provoca, además, el daño ocasionado al privarse indebidamente a la persona de sus derechos, de su capacidad jurídica, nombrándosele un representante que gobierne su vida en lugar de un mecanismo de apoyo o asistencia para la toma de decisiones personales y patrimoniales; incluso si después dicha decisión judicial fuera revocada en segunda instancia, es irreparable. Dicho esto, y de forma sucinta, es reseñable que los avances judiciales se han enfocado en dar preferencia al apoyo mediante curatela, relegando la tutela solo para aquellos casos en los que sea estrictamente necesaria la representación de la persona. 
A mi parecer, el actual procedimiento de modificación de la capacidad no se ajusta a dicho Instrumento internacional. No podemos seguir adelante recurriendo mayormente a la curatela en detrimento de la tutela, pero constriñendo a la persona a pasar, necesariamente, por una previa declaración judicial de incapacitación, a la cual se llega por medio de un juicio contradictorio que suele durar cerca de un un año. Ello no se ajusta ni mucho menos al sistema de apoyos previsto en la Convención. Para proteger a la persona no es preciso incapacitar. Nada avanzamos si nos limitamos a cambiar el término "incapacitación" por el de “modificación judicial de la capacidad". De lo que se trata es desplazar el centro de gravedad a la autonomía individual y autodeterminación de la persona con apoyos (solo cuando éstos sean necesarios) y no de mantenerla en el ámbito de la incapacidad.

En materia de alimentos y de guarda y custodia de los hijos con discapacidad, también se han dado pasos adelante en el terreno judicial.

Además, a raíz de la ratificación por España de la Convención y el compromiso, en consecuencia, asumido de adecuar nuestro Ordenamiento jurídico a los mandatos de aquélla, se han ido promulgando, sucesivamente, varias normas: la Ley 26/2011, de 1 de agosto y el Real Decreto 1276/2011, de 16 de septiembre, de adaptación normativa a la Convención Internacional sobre los Derechos de las Personas con Discapacidad; el Real Decreto Legislativo 1/2013, de 29 de noviembre, por el que se aprueba el Texto Refundido de la Ley General de derechos de las personas con discapacidad y de su inclusión social; la Ley Orgánica 1/2017, de 13 de diciembre, de modificación de la Ley Orgánica 5/1995, de 22 de mayo, del Tribunal del Jurado, para garantizar la participación de las personas con discapacidad sin exclusiones, según la cual, desde febrero de 2018, las personas con discapacidad ya pueden formar parte del jurado popular, lo que es conforme al art. 13 de la Convención; y la Ley Orgánica 2/2018, de 5 de diciembre, para la modificación de la Ley Orgánica 5/1985, de 19 de junio, del Régimen Electoral General para garantizar el derecho de sufragio de todas las personas con discapacidad.

Pese a los progresos en materia de derechos humanos y discapacidad sucintamente apuntados, aún quedan pendientes muchos retos.

Han debido transcurrir diez años para afrontar la reforma de la legislación 
civil y procesal en materia de discapacidad. En septiembre de 2018, el anterior Gobierno aprobó el anteproyecto de ley por la que se pretendía acometer dicha reforma, la cual, con mejoras técnicas en su texto, confío en que muy pronto, apenas acabemos con la parálisis normativa en que España lleva años inmersa a causa de los vaivenes políticos, pueda ver la luz. Sin poder entrar aquí en un análisis de dicha iniciativa legislativa, considero que está en sintonía con la Convención neoyorquina y su enfoque de derechos humanos al pretenderse, a toda costa, indagar la voluntad, deseos y preferencias de la persona con discapacidad, quedando relegado su interés, el cual evoca la decisión de un tercero.

No obstante, a diario siguen vulnerándose los derechos inherentes a la persona, lo que es intolerable tras algo más de una década de vigencia del Tratado de Nueva York en nuestro país. Las personas con discapacidad viven con muchos escollos o barreras que sortear: del entorno o físicas, actitudinales (por desinformación, indiferencia, prejuicios...) e institucionales (las discriminaciones refrendadas legalmente, así como la falta de cumplimiento efectivo de las disposiciones normativas). En cierto modo, seguimos la costumbre espartana de arrojar a las personas con discapacidad por el Monte Taigeto.

La educación inclusiva es, sin duda, una asignatura pendiente, al igual que la inclusión de las personas con discapacidad en el mercado laboral. Otra más es la accesibilidad, por la cual no ha de entenderse solo la física o arquitectónica, sino la universal, en la que se comprende, además, la sensorial y la cognitiva. En relación a esta última, concerniente a la supresión de barreras de compresión y comunicación, creemos necesario que en todas las normas en las cuales se regule el consentimiento informado se contemple que tanto la información previa como el proceso de prestación del consentimiento sean accesibles y comprensibles.

Al niño, niña y adolescente con diversidad funcional ha de prestársele mucha más atención. Debe respetarse su derecho a ser escuchado tanto en el ámbito familiar como en cualquier procedimiento que le afecte ex art. 9 de la Ley Orgánica 1/1996; su derecho al ocio; su derecho a una vida sexual y reproductiva, reconocido en el art. 23 de la Convención de Nueva York, pese a lo cual los niños y jóvenes con diversidad funcional suelen ser excluidos de los programas de salud sexual y de la reproducción y sobre el vIH/sida y otras enfermedades venéreas, al partir de la premisa de que no son sexualmente activos. Ni siquiera 
se les da información básica sobre los cambios que experimenta su cuerpo o sobre cómo están expuestos a correr un mayor riesgo de sufrir abusos. Como los demás, también tienen el derecho a la identidad de género. La combinación transexualidad y discapacidad parece imposible, y sin embargo es real.

Un importante sector del colectivo de las personas con discapacidad es el de las mujeres, las cuales presentan una problemática específica repleta de limitaciones. En este sentido, en relación al problema de la violencia de género, se ha constatado que la confluencia de factores como el género y la discapacidad convierte a las mujeres con diversidad funcional en un grupo con grave riesgo de sufrir algún tipo de maltrato. En cuanto al derecho a la salud, la mujer con discapacidad tiene numerosas barreras para acceder a la planificación familiar y a la asistencia a la reproducción. Aunque parezca mentira, en nuestro país, la esterilización forzosa sigue permitiéndose, normativamente; en concreto, en el art. 156 del Código penal: una flagrante violación de los derechos humanos de niñas y mujeres. ${ }^{4}$

En España queda mucho por hacer. Seguiremos trabajando para que las personas con discapacidad no encuentren obstáculos para ejercer, con dignidad y libertad, su derecho a una ciudadanía plena. ¿La meta? Construir juntos un mundo mejor, más inclusivo e igualitario.

Cómo citar el artículo: Vivas-Tesón, I. (2020). La reciente humanización del Derecho Civil Español: necesidades y retos en materia de discapacidad. Derecho Global, Estudios sobre Derecho y Justicia, V. (14) pp. 191-198

\footnotetext{
${ }^{4}$ Para un estudio en mayor profundidad acerca de la esterilización forzosa, vid. VIVAS TESÓN, I.: "El ejercicio de los derechos de la personalidad de la persona con discapacidad", en Claves para la adaptación del Ordenamiento jurídico privado a la Convención de Naciones Unidas en materia de discapacidad, DE SALAS y MAYOR DEL HOYO (dirs.), Tirant lo Blanch, Valencia, 2019, pp. 409-443.
} 